International Journal of Pure and Applied Mathematics

Volume 93 No. 5 2014, 647-659

ISSN: 1311-8080 (printed version); ISSN: 1314-3395 (on-line version)

url: http://www.ijpam.eu

doi: http://dx.doi.org/10.12732/ijpam.v93i5.6

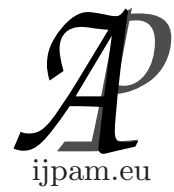

\title{
ASSESSMENT OF THE NON-STATIONARY TEMPERATURE FIELD IN A ROAD CONSTRUCTION WITH AN UNDERGROUND HEAT PIPELINE BY THE FINITE ELEMENT METHOD
}

\author{
B.B. Teltaev ${ }^{1}$, K. Aitbaev ${ }^{2} \S$ \\ ${ }^{1,2}$ Kazakhstan Highway Research Institute \\ Nurpeisov 2A, Almaty ,050061, REPUBLIC OF KAZAKHSTAN
}

\begin{abstract}
In this paper the results of solution of non-stationary heat conductivity for a city road construction with an underground heat pipeline by the finite element method are given. Significant influence of an underground heat pipeline presence on a temperature field in a road construction and the soil foundation is revealed.
\end{abstract}

AMS Subject Classification: 86-05, 86-08, 81T80, 80M10

Key Words: heat pipeline, non-stationary temperature field, road construction, finite element method, underground collector

\section{Introduction}

Deformations, occurring in a road construction can be caused not only by the action of a mobile load, but also by influence of climatic factors, namely, temperature effect on structural elements. Tension in a road construction, arising from the effects of environment temperature, strengthens under the influence of thermal networks operation located under the carriageway of urban streets and roads. Study of temperature mode of urban road constructions should include both theoretical and experimental researches directed on establishing regularities of temperature distribution in a ground foundation of urban roads and in structural layers of pavement. Strength and stability of road construc-

Received: January 26, 2014

(c) 2014 Academic Publications, Ltd.

$\S_{\text {Correspondence author }}$ url: www.acadpubl.eu 
tion operation during all maintenance term largely depend on regional features. Therefore, consideration of the influence of temperature mode on strength and durability operation of construction is an actual task during the construction and calculation pavement of urban streets and roads. The purpose of this paper is to create a mathematical model formation process of a non-stationary temperature field in a multi-layer road construction with an underground heat pipeline, tested on the results of a natural experiment. Natural experiment whose purpose was establishing formation regularities of real non-stationary temperature field in a road construction with an underground heat pipeline, was carried out in 2002-2003 in the conditions of Almaty city [1-2]. Description of the experimental section, the scheme of equipment by measuring instruments and methodology for conducting natural experiment, are provided in work [2]. Also, theoretical solution bases of the two dimensional task of stationary heat conduction by the finite element method, description of a mathematical model of researched process and the main results of numerical implementation of a mathematical model that has been tested on the results of a natural experiment are given. The present work is a natural extension of [2] and illuminates formation regularities of a non stationary temperature field in a multi-layer road construction with an underground heat pipeline.

\section{Theoretical Bases of a Mathematical Model}

Non-stationary heat conductivity in a plane body is described by a differential equation of parabolic type [3]:

$$
K_{x x} \frac{\partial^{2} T}{\partial x^{2}}+K_{y y} \frac{\partial^{2} T}{\partial y^{2}}+Q=\lambda \frac{\partial T}{\partial t}
$$

with boundary conditions

$$
K_{x x} \frac{\partial T}{\partial x} l_{x}+K_{y y} \frac{\partial T}{\partial y} l_{y}+h\left(T-T_{\infty}\right)+q=0,
$$

where $K_{x x}$ and $K_{y y}$ - coefficients convective heat conduction in the axes directions of coordinates, $\mathrm{kW} /\left(\mathrm{m}^{\circ} \mathrm{C}\right) ; \mathrm{h}$ - convective heat exchange coefficient between surface of a object and surrounding air, $k W /\left(m^{2}{ }^{\circ} \mathrm{C}\right) ; T$ - required body surface temperature, where occurs a convective heat exchange, ${ }^{\circ} C ; Q-$ source of heat inside the body, $k W / \mathrm{m}^{3} ; T_{\infty}-$ known surrounding air temperature, ${ }^{\circ} \mathrm{C}$; $l_{x}, l_{y}-$ direction cosines; $q$ - intensity of a heat stream, $\mathrm{kW} / \mathrm{m}^{2}$.

In the equation (1) member with a private derivative on time is considered as a function of coordinates in each fixed time point. 
For solution the equation (1) using variation principle, according to which, in case of achievement heat exchanging process of its steady state, the quantity of heat which has been accumulated by a body to this time point, reaches its minimum value. Sum of integrals by means of which the stored quantity of heat is calculated, is called functionality and has a form

$$
\begin{gathered}
\chi=\int_{V} \frac{1}{2}\left[K_{x x}\left(\frac{\partial T}{\partial x}\right)^{2}+K_{y y}\left(\frac{\partial T}{\partial y}\right)^{2}-2\left(Q-\lambda \frac{\partial T}{\partial t}\right) T\right] d V+ \\
+\int_{S_{1}} q T d S+\int_{S_{2}} \frac{h}{2}\left[T^{2}-2 T T_{\infty}+T_{\infty}^{2}\right] d S .
\end{gathered}
$$

Then the equation solution of heat conduction (1) reduces to minimizing the function (3) for each time interval.

As a result of finite-element discretization of the study area the required continuous function is in each finite element $T=T(x, y, t)$ by means of shape functions approximately has been replaced by vector of the discrete values of temperature $\{T\}$, defined in nodal points of finite-element area

$$
T=[N]\{T\}
$$

where the matrix $[N]$ contains shape function of the element. Then condition for achieving the functional (3) its minimum will be written as [3]

$$
\frac{\partial \chi}{\partial\{T\}}=0
$$

Methods minimizing the set of nodal values of the required temperature $\{T\}$ of the given functionality (3) detailed described in [3], and only the final result is given here. As a result of expression minimization (3) it turns out the system of the linear differential equations of the first order [3]:

$$
[C] \frac{\partial\{T\}}{\partial t}+[K]\{T\}+\{F\}=0,
$$

where matrix $[K],[C]$ and vector $\{F\}$ represent the sum of the contributions of each finite element:

$$
\begin{aligned}
& {[K]=\sum_{e=1}^{E}\left[k^{(e)}\right],} \\
& {[C]=\sum_{e=1}^{E}\left[c^{(e)}\right],}
\end{aligned}
$$




$$
\{F\}=\sum_{e=1}^{E}\left\{f^{(e)}\right\}
$$

In formulas (5)-(7) defined: $[K]-$ matrix of heat conduction of system; $[C]-$ matrix of damping of system; $\{F\}$-vector of nodal heat loads of system. Here, the contribution of each element in the matrix $[K],[C]$ and $\{F\}$ and expressed by the formulas

$$
\begin{gathered}
{\left[c^{(e)}\right]=\int_{V} \lambda[N]^{T}[N] d V} \\
{\left[k^{(e)}\right]=\int_{V}[B]^{T}[D][B] d V+\int_{S_{2}} h[N][N] d S} \\
\left\{f^{(e)}\right\}=-\int_{V} Q[N]^{T} d V+\int_{S_{1}} q[N]^{T} d S-\int_{S_{2}} h T_{\infty}[N]^{T} d S .
\end{gathered}
$$

All integrals in formulas (5)-(7) are taken by individual element. Summation of the contributions of individual elements are made in a usual form. For 2 dimensional simplex-elements the integral (5) is calculated as follows [3]:

$$
\left[c^{(e)}\right]=\frac{\lambda}{12}\left[\begin{array}{lll}
2 & 1 & 1 \\
1 & 2 & 1 \\
1 & 1 & 2
\end{array}\right],
$$

where $A-$ area triangular simplex-element, $\lambda=\rho c$. Density $\rho$ and specific heat capacity $c$ has dimensions $\mathrm{kg} / \mathrm{m}^{3}$ and $J /\left(\mathrm{m}^{3} \cdot{ }^{\circ} \mathrm{C}\right)$ respectively. To obtain significance $\{T\}$ at each point of the time interval, it is necessary to solve linear differential equation (4). In this paper, applied an approximate replacement method of a private derivative on time by its finite-difference analog using the central difference scheme [3]. As a result, the differential equation (4) is reduced to a system of linear algebraic equations:

$$
\left([K]+\frac{2}{\Delta t}[C]\right)\{T\}_{1}=\left([K]-\frac{2}{\Delta t}[C]\right)\{T\}_{0}-2\{F\}^{*}
$$

where $\{F\}^{*}=\frac{1}{2}\left(\{F\}_{1}+\{F\}_{0}\right)$. Here vectors of nodal heat loads $\{F\}_{0}$ and $\{F\}_{1}$ refers to a moments of time $t$ and $t+\Delta t$ respectively.

Considering the initial nodal values of temperature $\{T\}_{0}$ at a moment of time $t$ as known, nodal values at a moment of time $t+\Delta t$ can be obtained, by solving equation (12) concerning $\{T\}_{1}$.Column-vector $\{F\}^{*}$ contains the known parameters, therefore, it can be calculated till solution of the equation (12). 


\section{Implementation Results of a Mathematical Model}

Design scheme provided in operation [3], here is provided without special changes (Figure 1). Distinction is only, that vertical boundaries of researched area instead of the given temperature linearly changing on height, here taken the absence of heat flow $(q=0)$ in these sections.

All geometrical parameters and heat physical characteristics of a mathematical model are accepted same, as in operation [2].

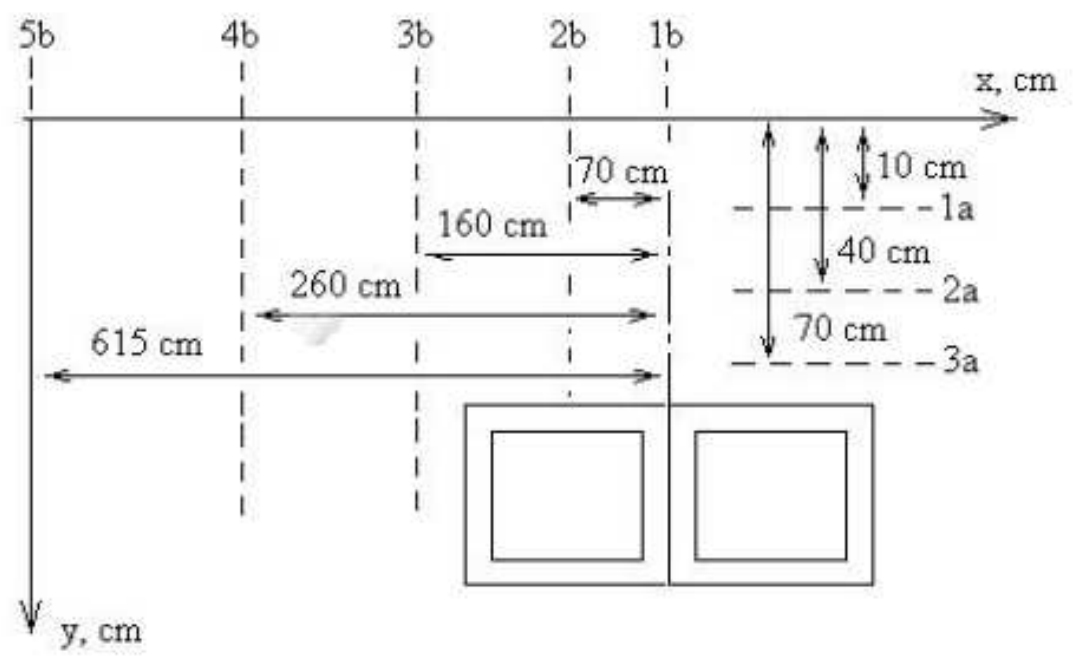

Figure 1: Boundary conditions in the non-stationary task of heat conduction. The reference designations: $T_{\infty}\left(t_{i}\right), T_{k 1}\left(t_{i}\right) T_{k 2}\left(t_{i}\right)$ - temperature of outside air and air temperature in the first and second collectors at current moments of time respectively

Research of a non-stationary temperature mode of considered area has been carried out for the range of change outside air temperature $T_{\infty}\left(t_{i}\right)$ from $-12.5^{\circ} \mathrm{C}$ to $-21.3^{\circ} \mathrm{C}$ that corresponds to data of a meteorological station of Almaty for January 1-2, 2008 from 6-00 morning to 24-00 night. Here $t_{i}-$ measuring time of outside air temperature, realizing every 3 hour. On a mathematical model the interval of time of calculation is accepted at 1 hour, missing intermediate temperature data are determined by linear interpolation way. The review of the published works showed that for determining the values of surface temperature of an asphalt concrete pavement the expressions including 
characteristics of convective heat exchange with an air environment $[4,5]$ are used. Regularities of air temperature change in ferro concrete pipes collectors of forward and reverse water flow of a heat conductor, depending on outside air temperature, are received by a method of reverse recount of natural experiment results [1-2] as:

$$
\begin{aligned}
& T_{k 1}=\left\{\begin{array}{l}
-0.93 \cdot T_{\infty}+48.51^{\circ} \mathrm{C}, \text { if } 4.1^{\circ} \mathrm{C}>T_{\infty} \geq-19.1^{\circ} \mathrm{C}, \\
66.28^{\circ} \mathrm{C}, \text { if } T_{\infty}<-19.1^{\circ} \mathrm{C} .
\end{array}\right. \\
& T_{k 2}=\left\{\begin{array}{l}
-0.69 \cdot T_{\infty}+30.69^{\circ} \mathrm{C}, \text { if } 4.1^{\circ} \mathrm{C}>T_{\infty} \geq-19.1^{\circ} \mathrm{C}, \\
0.51 \cdot T_{\infty}+53.61^{\circ} \mathrm{C}, \text { if } T_{\infty}<-19.1^{\circ} \mathrm{C} .
\end{array}\right.
\end{aligned}
$$

To analyze the results of calculation program made in MATLAB language $[6,7]$, in the calculation scheme characteristic sections are assigned (Figure 2). In figures 3-5 diagrams of temperature change are provided in horizontal sections 1a, 2a and 3a, located at a depth of $10 \mathrm{~cm}, 40 \mathrm{~cm}$ and $70 \mathrm{~cm}$ respectively, where under the sign of 1 diagrams are provided, appropriate time 15-00 hours, and the sign 2 marked the diagrams corresponding to time 24-00 hours.

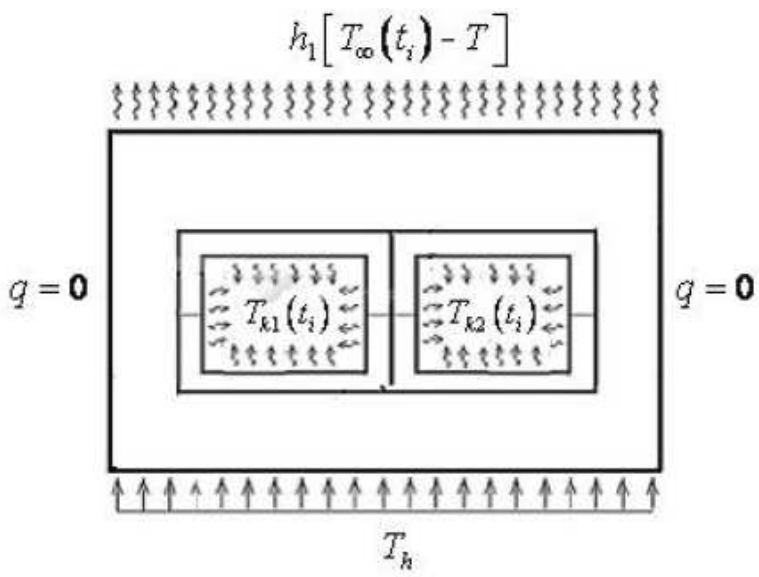

Figure 2: Characteristic sections in the calculation scheme 


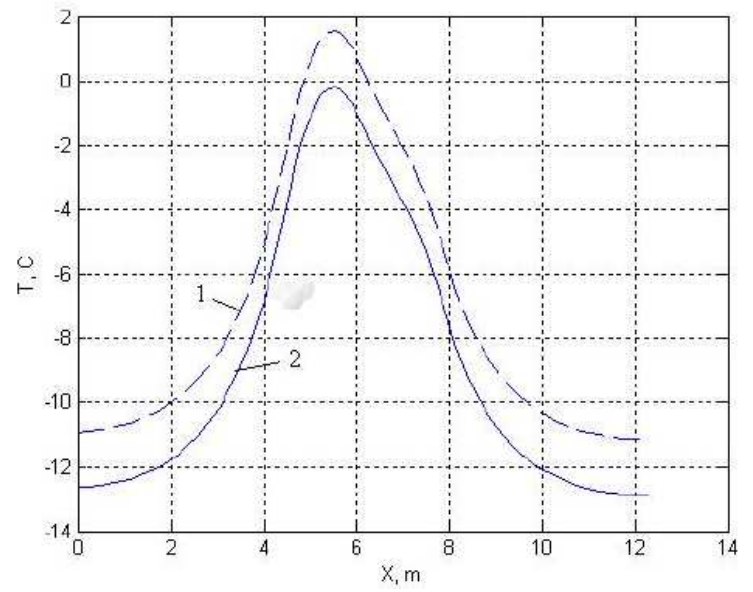

Figure 3: Diagrams of temperature change in section 1. corresponds to 15-00 hours, 2-corresponds to 24-00 hours

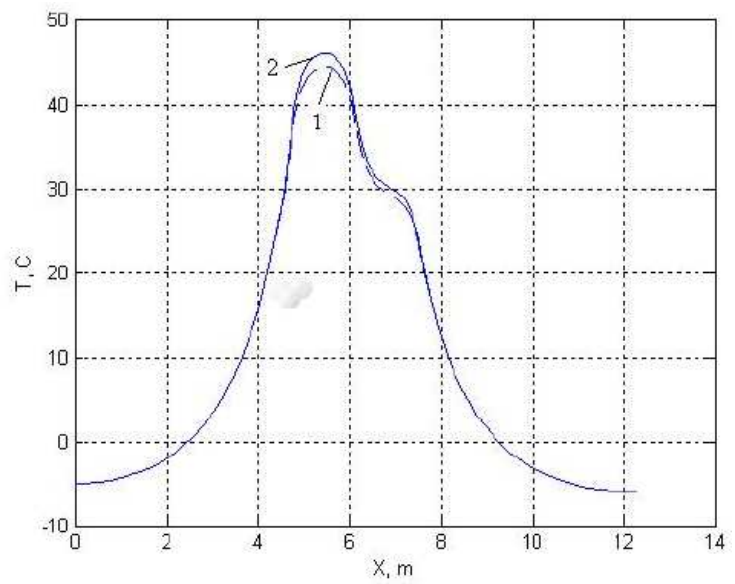

Figure 4: Diagrams of temperature change in section 3. 1-corresponds to 15-00 hours, 2-corresponds to 24-00 hours

In all figures clearly seen significant influence of underground heat sources. The diagrams corresponding to depth of $10 \mathrm{~cm}$ clearly react to changes of outside air temperature (figure 3 , section 1 ). The horizontal layer at this depth passes on a bottom of two-layer asphalt concrete. 


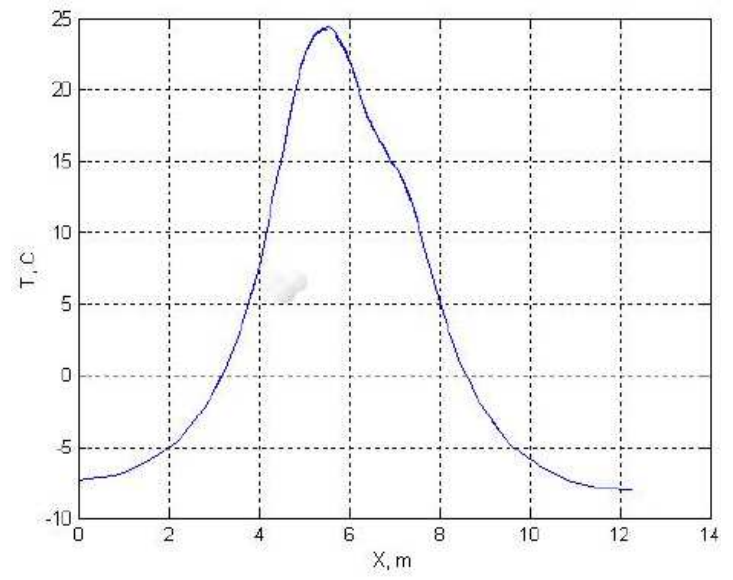

Figure 5: Diagrams of temperature change in section $2 \mathrm{a}$

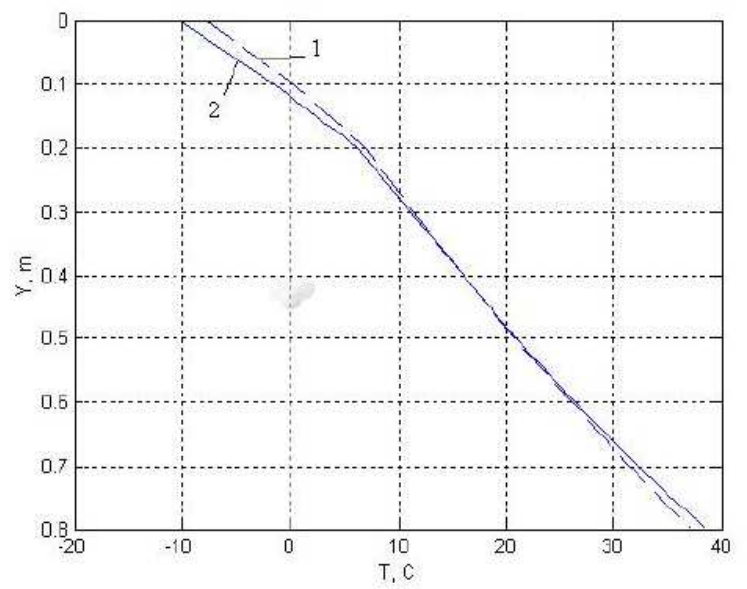

Figure 6: Diagrams of temperature change in section $1 \mathrm{~b}$. corresponds to 15-00 hours, 2-corresponds to 24-00 hours

Diagrams of temperatures created at a depth of $70 \mathrm{~cm}$ that passes at distance of $10 \mathrm{~cm}$ from the upper surface of underground collectors are given in a figure 4 (section 3a, figure 2). In this section the temperature field to changes of outside air temperature reacts on the contrary. The lower outside air temperature, the higher temperature of this horizontal cross-section. Such 


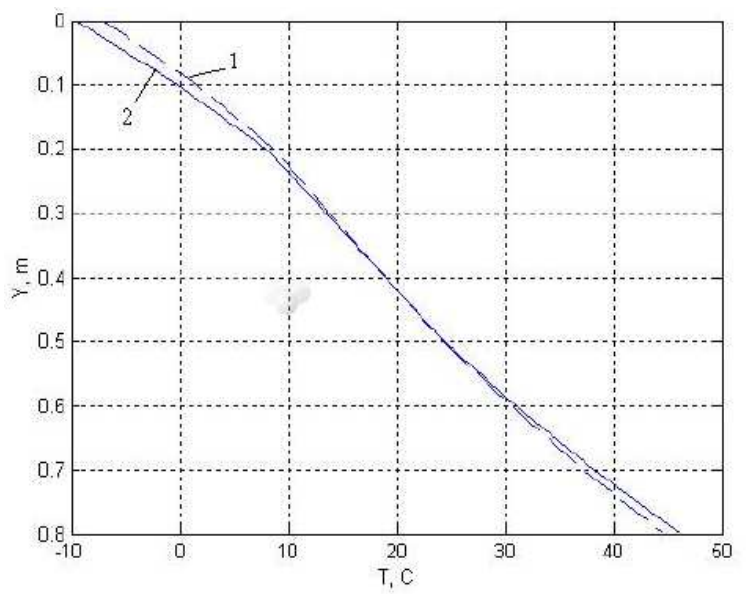

Figure 7: Diagrams of temperature change in section $2 \mathrm{~b}$. 1corresponds to 15-00 hours, 2-corresponds to 24-00 hours

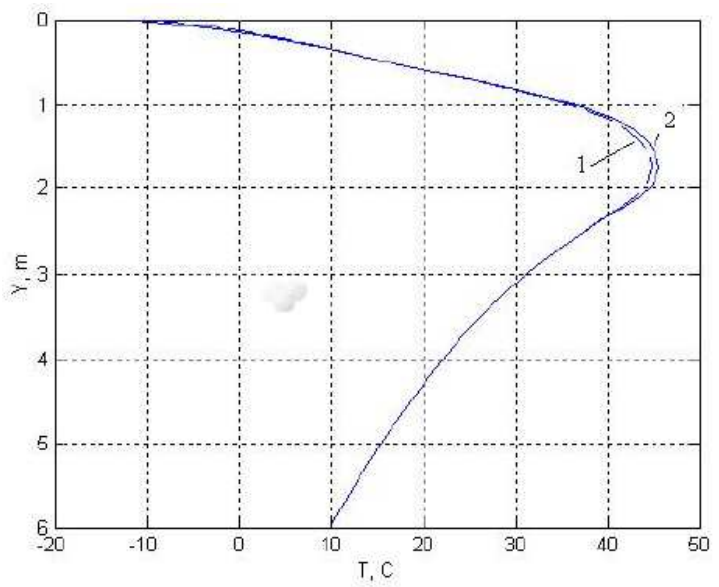

Figure 8: Diagrams of temperature change in section 3b. corresponds to 15-00 hours, 2-corresponds to 24-00 hours

phenomenon can be explained with compensating influence of temperature in a heat conductor pipes of the forward and reverse directions, which calculated by the formulas (13). With temperature drop of outside air, temperature in heat conductor pipes increases, i.e. the colder outside, the more heat is required for 


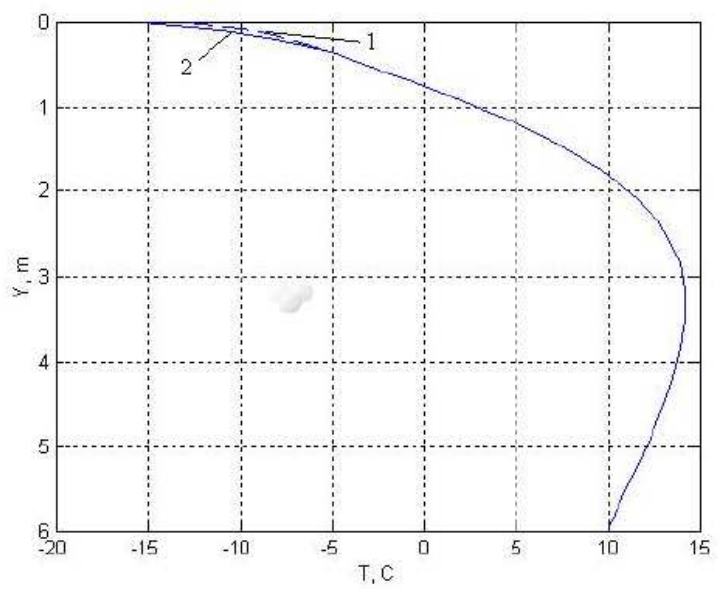

Figure 9: Diagrams o temperature change in section 4b. 1-corresponds to 15-00 hours, 2-corresponds to 24-00 hours

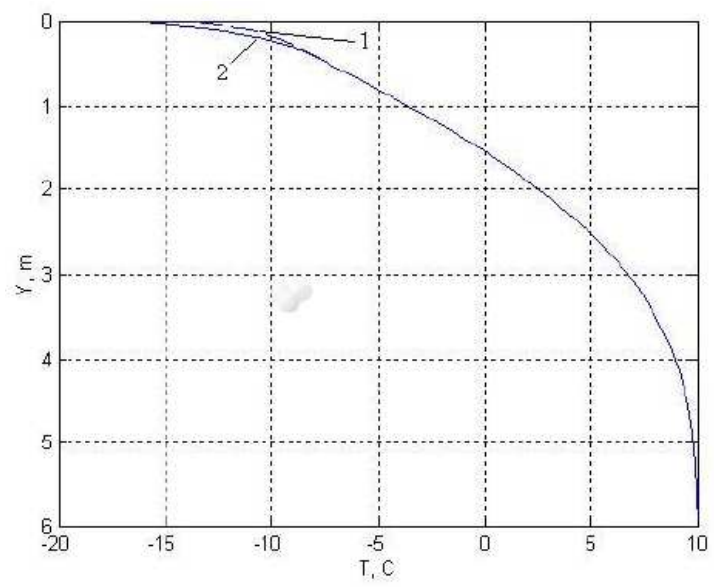

Figure 10: Diagrams of temperature change in section 5b. 1corresponds to 15-00 hours, 2-corresponds to 24-00 hours

domestic heating. In turn, on horizontal section 2, located at a depth of $40 \mathrm{~cm}$, on changes of outside air temperature was not observed any reaction, so in this section air temperature drop completely compensated by temperature increase in heat conductor pipes (a figure 5). 
The following series of numerical results are shown in figures 6-10. In figures 6 and 7 are shown changes of a temperature field in the sections, corresponding to a vertical axis of symmetry of researched area and a vertical axis of symmetry of the first collector (sections $1 \mathrm{~b}$ and $2 \mathrm{~b}$ a figure 2 ).

On character both figures match, although in Figure 7 the value of the positive temperature higher than in Figure 6, as section 2b passes over the feed pipe.

Figures 8-10 show non-stationary change of a temperature field in the vertical sections, remote from the central vertical axis of symmetry at distance of 160, 260 and $615 \mathrm{~cm}$ respectively. In vertical section 3b (figure 8) a temperature field entirely defined by influence of the underground heat source. Figure 9 shows that in section $4 \mathrm{~b}$ influence of an underground heat source are more spreading down the section. Figure 10 once again validates assignments of boundary conditions in the form of absence of heat exchange $(q=0)$ on vertical boundary of researching area, because there is not observed any temperature change in time. The only exception is the upper area of the cross section in close proximity to the upper horizontal boundary of researching area where influence of outside air temperature change is great.

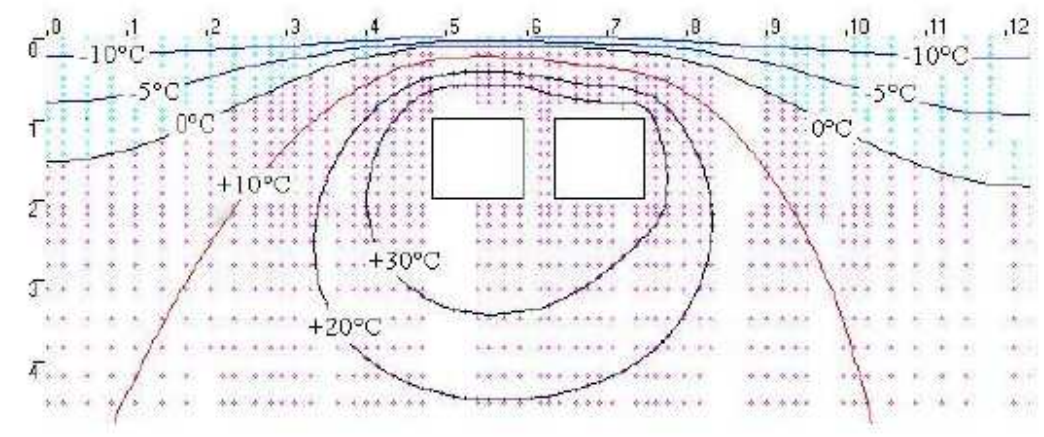

Figure 11: Isotherms of the temperature field at time 24-00 hours

The provided analysis of numerical results completely confirmed by a pattern of isothermal curves (figure 11), which corresponds to the end of considered time interval, namely, to 24-00 hour. Here the zero isotherms separate researched area into two parts. In the upper part of the isotherms picture the area of negative temperatures is formed. The most upper point of a zero isotherm passes at distance of $8 \mathrm{~cm}$ from the upper horizontal boundary of researched area.

Thus, it is set that under the influence of an underground heat pipeline 
in road construction forms the extensive zone with positive temperature which boundary passes close proximity to a pavement surface.

\section{Conclusions}

1. The task solution of non-stationary heat conduction for urban road construction with an underground heat conductor by the finite-element method is received.

2. Significant influence of an underground heat pipeline presence on a temperature field in a road construction and the soil base is revealed.

3. In winter time daily vibration of air temperature, causes temperature change only within asphalt concrete layers of road construction.

4. During the cold period base layers of road pavement and the ground base at distances to 3 cross sizes of a single collector in a horizontal direction from boundaries of collectors have a positive temperature.

\section{References}

[1] Sh.M. Aytaliev, B.B. Teltaev, K. Aytbaev, Kh.S. Tursumbekova, On complex study of the temperature regime of urban road constructions above an underground heat pipeline, News of Higher Educational Institutions, Construction, 12 (2003), 66-70.

[2] K. Aitbaev, S.N. Duysebaev, A.A. Kanibekova, Singularities of a temperature field in a road construction with an underground heat pipelin, International Journal of Pure and Applied Mathematics, 85, No. 1 (2013), 129-140.

[3] L. Segerlind, Application of Finite Element Method, Mir, Moscow (1979).

[4] B.H. Diefenderfer, I.L. Al-Qadi, S.D. Diefenderfer, Model to predict pavement temperature profile: Development and validation, Journal of Transportation Engineering (2006), 162-167.

[5] M.J.C. Minhoto, J.C. Pais, P.A.A. Pereira, L.G. Picado-Santos, Predicting asphalt pavement temperature with three-dimensional finite element method. Transportation research record, Journal of Transportation Research Board of the National Academies, Washington, D.C. (2005), 96-110. 
[6] V.N. Govorukhin, V.G. Tsibulin, The Computer in Mathematical Research, SPb:piter (2001), 624pp.

[7] N.N. Martynov, A.P. Ivanov, MATLAB 5.x. Computation, Visualization, Programming, Moscow, KUDITs-OBRAZ (2000), 335 pp. 
